Addendum Table 1. Statistical analysis of $\gamma-\mathrm{H} 2 \mathrm{AX}$ foci co-localization with $/ g$ alleles

\begin{tabular}{|c|c|c|c|c|c|c|}
\hline \multirow[b]{2}{*}{ Genotype } & \multicolumn{2}{|c|}{ Pre-pro-B, Igh } & \multicolumn{2}{|c|}{ Pro-B, Igh } & \multicolumn{2}{|c|}{ Pre-B, Igk } \\
\hline & WT & $\mathrm{Atm}^{-1-}$ & WT & $\mathrm{Atm}^{-1-}$ & WT & $\operatorname{Atm}^{-1-}$ \\
\hline Total number of cells & 894 & 841 & 885 & 729 & 906 & 1024 \\
\hline Cells with $\gamma-\mathrm{H} 2 \mathrm{AX}$ on one allele & 89 & 115 & 81 & 115 & 158 & 193 \\
\hline Cells with $\gamma-\mathrm{H} 2 \mathrm{AX}$ on two alleles & 2 & 14 & 2 & 8 & 5 & 49 \\
\hline $\begin{array}{l}\chi^{2} \text { statistical test } \\
P \text { value mono and biallelic } \\
P \text { value monoallelic } \\
P \text { value biallelic }\end{array}$ & \multicolumn{2}{|c|}{0.00078251} & \multicolumn{2}{|c|}{0.0000459} & \multicolumn{2}{|c|}{0.00000014} \\
\hline
\end{tabular}

Number of cells in Addendum Figure 1. These numbers analyzed differ from those originally published, as new experiments have been added. The $\chi^{2}$ test was used to determine whether differences were significant; the Yates correction was used when any value was $<10$. ' $P$ value monoallelic and biallelic' compares the total cell populations; ' $P$ value monoallelic' examines whether the difference in populations was due to the incidence of monoallelic association; and ' $P$ value biallelic' indicates in the pre-pro-B and pre-B populations, the statistically significant difference was in the biallelic association of $\gamma-\mathrm{H} 2 \mathrm{AX}$. Data are composite of three independent experiments.

\begin{tabular}{|c|c|c|}
\hline Stage/mono or bi & Contingency & $P$-value \\
\hline pre-pro-B & $2 \times 3$ & 0.0007 \\
\hline pre-pro-B mono & $2 \times 2$ & 0.0457 \\
\hline pre-pro-B bi & $2 \times 2$ & 0.0021 \\
\hline pro-B & $2 \times 3$ & 0.0001 \\
\hline pro-B mono & $2 \times 2$ & 0.0005 \\
\hline pro-B bi & $2 \times 2$ & 0.0527 \\
\hline pre-B & $2 \times 3$ & $1.1925 \mathrm{e}-07$ \\
\hline pre-B mono & $2 \times 2$ & 0.7715 \\
\hline pre-B bi & $2 \times 2$ & $2.6047 \mathrm{e}-08$ \\
\hline
\end{tabular}

Reanalysis of the data in Addendum Figure 1 and Addendum Table 1 with Fisher's exact test to determine statistical significance. The conclusions of the results are not changed by the use of either statistical test.

\title{
Corrigendum: RAG-1 and ATM coordinate monoallelic recombination and nuclear positioning of immunoglobulin loci
}

Susannah L Hewitt, Bu Yin, Yanhong Ji, Julie Chaumeil, Katarzyna Marszalek, Jeannette Tenthorey, Giorgia Salvagiotto, Natalie Steinel, Laura B Ramsey, Jacques Ghysdael, Michael A Farrar, Barry P Sleckman, David G Schatz, Meinrad Busslinger, Craig H Bassing \& Jane A Skok

Nat. Immunol. 10, 655-664 (2009); published online 17 May 2009; corrected after print 18 May 2009, 19 August 2009 and 12 March 2010 ; addendum published online 12 March 2010.

In the version of this article initially published, two values on page 657, the title to Figure 3 and several Supplementary Table citations are incorrect. Sentence 2 of paragraph 2 on page 657, column 2, should end "than those in similar wild-type populations (55\% and 61\%, respectively)." The title for Figure 3 should begin "RAG-1 cleavage marks paired immunoglobulin alleles differently...." The Supplementary Table citations should be as follows: Figure 3 legend, “(complete statistical results, Supplementary Tables 4-6)”; Figure 5 legend, “(complete statistical results, Supplementary Tables 1, 2, 4, 5, 7 and 8)"; Figure 8 legend, “(complete statistical results, Supplementary Tables 1, 5 and 12)”; and page 662, column 2, sentence 2 "Supplementary Tables 1 and 4." The errors have been corrected in the HTML and PDF versions of the article. 